INTERNATIONAL RESEARCH JOURNAL OF PHARMACY
moksha
pusLshing House

\title{
AN OVERVIEW ON BLOOD PURIFIER
}

\author{
Sabia Chauhan* \\ Department of Pharmacology, CT Institute of Pharmaceutical Sciences, Shahpur, Jalandhar, Punjab, India \\ *Corresponding Author Email: sabiachauhan09@gmail.com
}

Article Received on: 16/08/13 Revised on: 04/09/13 Approved for publication: 11/09/13

DOI: $10.7897 / 2230-8407.04903$

IRJP is an official publication of Moksha Publishing House. Website: www.mokshaph.com

(C) All rights reserved.

\section{ABSTRACT}

Blood is a connective tissue which protects us from different problems. Without blood body cannot functions at all and blood doesn't purify itself. When blood does not purifies itself that times kidney, liver and lymphatic system work together that they help's to purifiers the blood. Causes which are included in blood impurities are modern life style, junk food, alcohol etc. If the blood becomes impure it causes different problems e.g. acne, rashes, allergic etc. There is not any proper synthetic medication for blood impurities. Only herbal formulations are used for the blood purifier. In this review article we discussed about the market formulations and the different plants which are used in them with their different activities which are helpful in purifies the blood and also protects from other problems.

Keywords: Blood, Blood purifier, Market formulations

\section{INTRODUCTION}

Blood in our body keeps us alive. It is a liquid connective tissue that consists of cells surrounded by a liquid extracellular matrix. The extracellular matrix is called blood plasma, and it suspends various cells and cell fragments. Blood is a specialized bodily fluid in animals that deliver necessary substances such as nutrients, hormones and oxygen to the cells and transport metabolic waste. It also removes waste and toxins from our system in order to keep healthy. It protects us from illness, infection and helps to heal cuts, scrapes and wounds. It is slightly alkaline $\mathrm{pH}$ ranging from 7.35 to $7.45^{1}$. While the blood in the body does have a way of purifying itself, that time it needs a little extra help. The kidney, liver and lymphatic system work together to rid the unwanted toxins and impurities form the body system, but sometimes it is too much, and the toxins start to build up which can affect the blood and muscle tissues in a negative way. When liver does not work properly then digestion become poor and the blood making procedure becomes impaired and the blood get impure ${ }^{2}$.

\section{Blood Purifier}

When our blood gets impure it firstly effect on the skin. Skin care is part of healthy lifestyle. Skin covers outer body, from dust, pollution, seasonal changes etc. Mild and chronic diseases affecting our skin due to bad habits in our life style. Skin diseases are caused by environmental factors like the presence of bacteria or viruses. Genetic factors also contribute to the development of a numbers of problems. Skin diseases are relatively minor, as they do not any pain or discomfort. Skin disease could be quite serious and perhaps even life threatening. Skin diseases can be mainly of four types: bacterial, viral, fungal, congenital skin diseases ${ }^{3}$. When blood impure due to bad circulation of blood it causes diseases like acne, pustules and rashes, complications produced from allergies, weak immune system, headache, jaundice, wrinkles on faces, spinning of head, hair loss, weakening eyesight, clamping of joints etc are the general symptoms of blood impurity ${ }^{4}$.

\section{Causes of Blood Impurities}

Modern life style has influenced our daily routine to a greater extent bringing in furious changes in our dietary habits and lifestyle in its wake as a result. On the other hand, the rising pollution in the environment has influenced us immensely not only from outside but from our inside within too. The bacteria spread in the environment, gases, polluted water, insomnia, junk foods, late night watching TV, keeping awake, skipping breakfast, incomplete sleep, junk foods, improper breathing, bedrooms not properly ventilated, and lack of exercise, drinking impure water and other harmful drinks, such as: tea, coffee, liquor, soft and drinks, worry, fear, anger, unhappiness etc has tightened its vice grips over the purity of our blood. These entire poisonous elements are entering inside our body giving invitations to several diseases ${ }^{4,5}$.

\section{Benefits of Blood Purifier}

There are not any synthetic medication used for blood purifier that are helpful to purify the blood and helpful for different problems that caused by blood impurities. There are different drugs for the every problem which are related to blood impurities e.g. acne: clindamycin, erythromycin, tetracycline etc, immunomodulators: cyclosporine, tacrolimus etc, for Inflammation: ketoprofen, ibuprofen etc. If these medications are given to a person it effect on the disease but only one disease is cure by that and these medications also shows the side effects. Blood purifier we can use the herbal medications which are helpful to solve these problems with less side effects in herbal medications we use Poly herbal formulation. Blood purifier is helpful in increased the bowel movement at the beginning which is a temporary phase. It takes two or three days, which is recommended because it is very supportive to the blood cleaning process. Either takes small doses in the beginning and increases after two or three days or starts the recommended dose and clear the bowel movement. It activates the sluggish liver and kidney to makes it healthy and more active. With purification of our system our skin gets more healthy, lustrous, smooth and silky with natural glow. A healthy skin is less prone to diseases and infections ${ }^{4}$. 
Herbal Market Formulations as Blood Purifier

Ancient time's plants have been exemplary source of medicine. Ayurveda and other Indian literature mention use of plants in the treatment of various human ailments. Researchers conducted on herbs mentioned in the ancient text or used traditionally for Gynaecological ailments have shown remarkable results. Herbal extracts in amycordial are enriched sources of several, micronutrients, bioflavonoid, glucosides, tannins, phytoconstituents. That help restore hormonal balance, tone endomertrium, improve capillary permeability improve fertility restore menstrual cycle, relief from various infections even prevent from recurrent conditions. These herbs also help maintain normal physiology and nutritional status of a woman. Different herbal plants which are used in Poly herbal formations that they give their best result with their combinations. There are different market formulation which are helpful in purifying the blood e.g. safi from hamdard, active blood purifier from dabar, raktamrut syrup from bellan pharmaceutical, musaffeen syrup from qarshi, blood purifier syrup from kismat medicare private limited, surakta from baidyanath, purodil from aimli pharmaceuticals etc. In this review we discuss different herbal plants which are useful in blood purifying and cleaning and which are common in different market formulations.

\section{Neem (Azadirachta indica) Family: Meliaceae}

It is one of the most important detoxicants in Ayurvedic medicine and is used widely for its antiseptic properties. Azadirachta indica has been revalidated for a pronounced anti-microbial action against a wide range of Gram +ve and Gram -ve bacteria ${ }^{6}$. Azadirachta indica significantly attenuates the stress induced suppression of humoral immune response. Azadirachta indica enhances the humoral anti-body response to the antigen, and hence boosts the immune system. Azadirachta indica suppresses inflammatory mediators in acne pathogenesis ${ }^{7}$.

Yashtimadhu (Glycyrrhiza glabra) Family:Fabaeceae It is the second most prescribed herb in China followed by Ginseng. Glycyrrhiza glabra shows remarkable anti-bacterial activity against Propionibacterium acnes, resulting in negligible induction of resistance. Flavonoids Glabridin and Glabrene isolated from Yashtimadhu were found to exhibit anti-methicillin resistant $S$. aureus activity. Phytoconstituent of Glycyrrhiza glabra effectively decreases one of the most potent classes of inflammatory mediators ${ }^{8}$. Immunomodulatory activity of Yashtimadhu helps in recovery of decreased cellular immunocompetence ${ }^{9}$.

Guduchi (Tinospora cordifolia) Family: Menispermaceae Guduchi plant is used as a medicine to improve the immune system and body's resistance against infections. It has a significant action as an immunomodulator. Tinospora cordifolia also showed a good protective effect on the mast cells, jaundice, fever and skin diseases, antiallergic etc properties ${ }^{10}$. Antioxidant activity of extract from roots shows that it is an effective natural antioxidant hence prevents radical damage in the body ${ }^{11}$.

\section{Manjitha (Rubia cordifolia) Family: Rubiaceae}

It has a long history of use in Ayurvedic medicine. It is a bitter-sweet, cooling herb that reduces inflammation and has anti- bacterial effects. It stimulates the circulation and resolves skin disorders ${ }^{12}$. Inhibition of Propionibacterium acnes-induced mediators of inflammation by Rubia cordifolia is observed. Rubia cordifolia, show statistically significant anti-inflammatory activity by suppressing the capacity of Propionibacterium acnes induced inflammation ${ }^{13}$.

\section{Haridra (Curcuma longa) Family: Zingiberaceae}

The primary active principle in Curcuma longa, have been claimed to represent a potential antioxidant and antiinflammatory agent with phytonutrient and bioprotective properties. Free radicals have been shown to exert deleterious effects on skin and are thought to be involved in ageing ${ }^{14}$. Curcumin the spice principle of turmeric (Curcuma longa) is a natural yellow orange dye and a good inhibitor of lipid oxidation. Studies demonstrates that Curcuma longa pre treatment has a conducive effect on the irradiated wound and is a substantial therapeutic strategy in initiating and supporting the cascade of tissue repair processes in irradiated wounds ${ }^{15}$.

\section{Sariva (Hemidesmus indicus) Family: Asclepiadaceae}

The drug has long enjoyed a reputation as a tonic, alterative and blood purifier. Hemidesmus indicus is a well known drug in Ayurveda system of medicine ${ }^{16}$. The extract of Hemidesmus indicus root barks, has anti-oxidant properties. The free radical scavenging property may be one of the mechanisms by which this drug is effective in several free radical mediated disease conditions. Moreover it also possesses anti-inflammatory activity ${ }^{17}$.

\section{Chopchini (Smilax china) Family: Smilacaceae}

Chopchini works as Blood cleanser, immunomodulator (selectively reduces over active immune cells), antimutagenic (cellular protector), detoxifier and tonic (tones, balances, strengthens overall body functions). The extract from Smilax china root has been used as medicinal remedy and reported to retain antimicrobial and anti mutagenic activities. Smilax china possesses free radical scavenging activity and protective property of cell's viability, suggesting that the medicinal component of the root of Smilax china extracts also contain antioxidant activity ${ }^{18}$.

Kalmegh (Andrographis paniculata) Family: Acanthaceae Kalmegh is a blood purifier. It is used as a cure for torpid liver and jaundice. It is a major constituent of the Ayurvedic preparation for skin disorders Hepato-protective and hepatocorrective components improve the process of detoxification and hence prevent the skin disorders ${ }^{19}$. Kalmegh has a profound anti-microbial effect, by showing potent, antibacterial (against $S$. aureus), anti-viral, anthelminthic (against Ascaris lumbricoides), ant malarial activity ${ }^{20}$. Kalmegh possess significant anti-passive cutaneous anaphylaxis, thus proves to be a potent anti-allergic, also enhances immunity by exerting immunomodulatory effect. Moreover Kalmegh has protective effects on heart by showing, antiatherosclerotic activity, anti-hyperglycaemic, and antihypertensive effects $^{21}$.

\section{Khadir (Acacia catechu) Family: Fabaceae}

Khadir extract is used as an immunomodulatory, purify blood, anodyne, astringent, bactericide, refrigerant, detergent, stimulant, styptic, masticatory, expectorant and antiphogistic. Khadir has astringent cooling and digestive properties. Khadir is also used in allergic conditions, colic, diarrhoea and dysentery, boils, in skin afflictions, bed sores, stomatitis, hepatoprotective, antifungal, hypoglycemic activity. To 
inhibit growth of micro-organisms, as an anthelminthic, antipyretic, anti-inflammatory, in bronchitis, ulcers, psoriasis, anaemia and gum troubles and has been also used to treat leprosy $y^{22}$.

\section{Tulsi (Ocimum sanctum) Family: Labiatae}

Tulsi extract is used in management of all skin diseases, antistress/adatogenic, antioxidant, immunomodulators ${ }^{23}$. The linolenic acid present in tulsi has the capacity to block both the cyclooxygenase and lipoxygenase pathways of arachidonate metabolism which could be responsible for the anti inflammation activity of the oil and hence helpful to decrease the inflammation with acne ${ }^{24}$.

\section{Bakuchi (Psoralea corylifolia) Family: Leguminosae}

Bakuchi is used in treatment of variety on skin problems, such as leukoderma, skin rashes, infections and others. Roots, stems, leaves, seeds and blooms are used for skin problems. Every part of plant shows different activity ${ }^{25}$.

\section{Chitra (Berberis aristata) Family: Berberidaceae}

Chitra extract used as a inflammation, wound healing, skin disease, blood purifier, diarrhoea, jaundice and affection of eyes. Pharmacological studies on the plant show antioxidant, antibacterial, antifungal, antipyretic, anti-inflammatory, hepatoprotective, Plant fruit is edible and it is rich in vit- $\mathrm{C}^{26}$.

\section{Aloe Vera (Aloe barbadensis) Family: Liliacaeous}

In Ayurveda, a traditional system of medicine, aloe vera is commonly used in sunburn, minor cuts, insect bites and used as wound healing, anti-inflammatory, antiviral, antitumor, laxative and in the treatment of frostbite and psoriasis. The whole plant as well as its specific parts (leaves, roots), plant extracts and its active constituent mucopolysaccharides (long chain sugars) have been widely used as antiseptic, antiinflammatory, anti-viral, antitumor and immunomodulators ${ }^{27}$. Indian system of medicine in India and its use for hepatic ailments is also documented ${ }^{28}$.

\section{CONCLUSION}

Herbal blood purifiers have not single activity they have multiple activity due to poly herbal formulation with lesser side effects. There are different herbal formulations in market which shows the activity of blood purifier mainly and these formulations contain common plants which we discuss in review. These formulation's not shows only blood purifier property but also have other properties like antibacterial, antifungal, immunomodulators, affection's of eyes etc. These formulations have greater effect then their side effects. There is not any specific blood purifier in synthetic medication.

\section{REFERENCES}

1. Tortora Gerard J and Derrickson Bryan. Principle of anatomy and physiology.13 ${ }^{\text {th }}$ ed: John Wiley and Sons, Inc; 2012. p. 634-635.

2. Atharva Ayurveda Pharmaceutical [home page on the internet]. India: Association of authentic Ayurvedic herbal products. Available from: http://atharva-ayurved.comhealth_helpblood_impurities.html; 1992.

3. Bellan Pharmaceutical [home page on the internet]. India: Association of Ayurvedic medicine. Available from: http://www.bellanayurvedic. com/bloodpurifier.html; 1991

4. Sagar Ayurvedic Pharmacy [home page on the internet]. India: Association of herbal formulations. Available from: http://www.satveda.com/home.php; 1932.

5. Kumar Ashish. Impurity in blood: its symptoms, causes and preventive measures. Available from: http://www.indiastudychannel.comr sources150766-Impurity-blood-Its-symptoms-causes.aspx.
6. Nand Pratibha, Drabu Sushma and Gupta Rajinder K. Insignificant antiacne activity of Azadirachta indica leaves and bark. Journal of pharmaceutical negative result. 2012;3(1).

7. Bhuiyan Md Mohashine, Nishimura Michiko, Matsumura Seishi and Shimono Tsutomu. Antibacterial effects of the crude Azadirachta indica Neem bark extract on Streptococcus sobrinus. Pediatric Dental Journal 1997; 7(1): 61-64.

8. Saxena Sanjai. Glycyrrhiza glabra: Medicine over the millennium. Natural product radiance; 2005. p. 358-367.

9. Papiya Mitra Mazumder, Shaktiprasad Pattnayak, Hitesh Parvani, Dinakar Sasmal, Paramaguru Rathinavelusamy. Evaluation of immunomodulatory activity of Glycyrhiza glabra L roots in combination with zing. Asian Pacific Journal of Tropical Biomedicine 2012: 15-20.

10. Sinha Kirti, Mishra NP, Singh JN and Khanuja SPS. Tinospora cordifolia (Guduchi), a reservoir plant for therapeutic applications: A review. Indian journal of traditional knowledge 2004; 3(3): 257-270.

11. Sankhala LN, Saini RK and Saini BS. A review on chemical and biological and biological properties of Tinospora cordifolia. Int. J. med. arom. plants 2012; 2(2): 340-344.

12. Karodi R, Jadhav M, Rub R, Bafna A. Evaluation of the wound healing activity of a crude extract of Rubia cordifolia L. (Indian madder) in mice. International Journal of Applied Research in Natural Products 2009; 2(2): 12-18.

13. Gorle Archana M, Patil Swati S. Evaluation of antioxidant and antiacne property of Rubia cordifolia. Der Pharmacia Sinica 2010; 1(3): 59-63.

14. Thanigavelan V, Kaliyamurthi V, Pitchiah M. Kumar, Elansekaran S and Victor G Rajamanickam. An overview of the Herbs in a Siddha Poly herbal decoction-Pidangunaari Kudineer indicated for Hepatomegaly. Journal of Applied Pharmaceutical Science 2012; 2 (7): 8-14. http://dx.doi.org/10.7324/JAPS.2012.2702

15. Agarwal SS and Singh VK. Immunomodulators: A review of studies in Indian medicinal plants and synthetic peptides. PINSA;1999.p.179-204.

16. Austin Anoop. A review in Indian Sarsaparilla, Hemidesmus indicus (L.) R.Br. Journal of biological sciences 2008; 8(1): 1-12.; 1(2): 91-100.

17. Murali Anita, Ashok Purnima and Madhavan Varadharajan. Antioxidant activity of leaf of Hemidesmus indicus (L.) R. Br. var. pubescens (W. and A.) Hk.f. (Periplocaceae) -an in vivo analysis. Spatula DD 2011; 1(2): 91-100.

18. Vijayalakshmi A, Ravichandiran V, Malarkodi Velraj, Nirmala S, Jayakumari S. Screening of flavonoid, quercetin, from the rhizome of Smilax china Linn. for anti-psoriatic activity. Asian Pac J Trop Biomed 2012; 2(4): 269-275. http://dx.doi.org/10.1016/S2221-1691(12)60021-5

19. Shahid Akbar. Andrographis paniculata: A review of pharmacological activities and clinical effects. Alternative medicine review 2011; 16: 6677. PMid: 21438648

20. Chowdhury Anusua, Biswas Subrata Kumar, Raihan Sheikh Zahir, Das Joysree and Pal Swati. Pharmacological potentials of Andrographis paniculata: An overview. International journal of pharmacology 2012; 8(1): 6-9. http://dx.doi.org/10.3923/ijp.2012.6.9

21. Niranjan Abhishek, Tewari SK, Lehri Alok. Biological activities of Kalmegh (Andrographis paniculata Nees) and its active principle-A review. Indian journal of natural products and resources 2010; 1(2): 125135.

22. Syed Ismail And Mohammed Asad. Immunomodulatory activity of Acacia Catechu. Indian J physiol pharmacol 2009; 53(1): 25-33. PMid: 19810573

23. Singh N, Verma P, Pandey BR, Bhalla M. Therapeutic Potential of Ocimum sanctum in Prevention and Treatment of Cancer and Exposure to Radiation: An Overview. Journal of Pharmaceutical Sciences and Drug Research 2012; 4(2): 97-104.

24. Kapoor Shweta and Saraf Swarnlata. Topical herbal therapies an alternative and complementary choice to combat acne. Research Journal of medicinal plant 2011; 5(6): 650-669. http://dx.doi.org/10.3923 /rjmp.2011.650.669

25. Khushboo PS, Jadhav VM, Kadam VJ, Sathe NS. Psoralea corylifolia Linn- Khushtanashini. Pharmacogn Rev 2010; 4(7): 69-76. http://dx. doi.org/10.4103/0973-7847.65331PMid:22228944

26. Sharma Komal, Bairwa Ranjan, Chauhan Neelam, Shrivastava Birendraand, Saini Neeraj Kumar. Berberis Aristata: A review. Int. J. Res. Ayurveda Pharm 2011; 2(2): 383-388.

27. Agarwal Shilpi, Sharma TR. Multiple Biological Activities of Aloe barbadensis (Aloe Vera): An Overview. Asian Journal of Pharmacy and Life Science 2011; 1(2).

28. Kumar Vivek R, Kumar Satish, S Shashidhara, S Anitha, M Manjula. Comparison of the antioxidant capacity of an important hepatoprotective plants. International Journal of Pharmaceutical Sciences and Drug Research 2011;3(1): 48-51.

Cite this article as:

Sabia Chauhan. An overview on blood purifier. Int. Res. J. Pharm. 2013; 4(9):8-10 http://dx.doi.org/10.7897/2230-8407.04903 